\title{
Current status and perspectives of PET molecular imaging in
} Mexico

\author{
Miguel Ángel Ávila-Rodríguez,, ${ }^{1 *}$ Belén Rivera-Bravo, ${ }^{2}$ Nora E. Kerik-Rotenberg, ${ }^{3}$ Enrique Vallejo, ${ }^{4}$
} Michel Herranz-Carnero ${ }^{5}$ and Christian Buelna-Cano ${ }^{4}$

${ }^{1}$ Universidad Nacional Autónoma de México, Faculty of Medicine, Radiopharmacy-Cyclotron Unit, Ciudad de México, Mexico; ${ }^{2}$ Universidad Nacional Autónoma de México, Faculty of Medicine, PET/CT Unit, Mexico City, Mexico; ${ }^{3}$ nstituto Nacional de Neurología y Neurocirugía, PET/CT Molee ular Imaging Unit, Mexico City, Mexico; ${ }^{4}$ Centro Médico ABC, Cardiovascular Center and Cardiovascular Imaging, Mexico City, Mexico; ${ }^{5}$ Servicio Gallego de Salud, Molecular Imaging in Oncology, Galicia, Spain

\begin{abstract}
Positron-emission tomography (PET) is a medical diagnostic technique by means of which functional images are obtained by recording the spatio-temporal biodistribution of specific radiopharmaceuticals targeted at specific molecular objectives, which provides biochemical information at the molecular level. Early in the first decade of this $21^{\text {st }}$ century, the Faculty of Medicine of the National Autonomous University of Mexico acquired the technology to implement this diagnostic technique in Mexico, thus becoming a pioneer in PET applications in the country and in Latin America. Almost two decades after its implementation in Mexico, PET has become an essential tool in medical clinics. This article describes the background, current state and̄perspectives of PET molecular imaging in Mexico, and the impact it has had on the management of patients with oncological, neurological and heart diseases.
\end{abstract}

KEY WORDS: Positron-emission tomography. PET in Mexico. Molecular imaging. Functional images.

\section{PET molecular imaging and radiopharmaceuticals}

\author{
Miguel Ángel Ávila Rodríguez
}

Positron-emission tomography (PET) molecular imaging is a medical diagnostic imaging technique that provides biochemical or functional information at the molecular and cellular level of biological processes. Developed in the mid-1970s, it was introduced in Mexico by the Faculty of Medicine of the National Autonomous University of Mexico early in the year 2000, when this institution acquired a cyclotron and a PET camera and created the PET-Cyclotron Unit, thus becoming a PET pioneer in Mexico.

\section{PE molecular imaging in Mexico}

Currently, in Mexico there are eight cyclotrons in operation (Table 1), half of them in Mexico City, and only two belong to public institutions: the one at the National Autonomous University of Mexico and that of the National Cancer Institute, which started operating in 2017. Regarding PET/computed tomography (CT) cameras, there are already 50 in the country: 29 in Mexico City and the others distributed in the rest of the states (Fig. 1). Ten PET/CT cameras belong to public institutions, two to universities (National Autonomous University of Mexico and Autonomous Un⿳亠丷厂̈rsity of Nuevo León), one to a private assistance insstitution (Telethon Children's Oncology Hospital, Querétaro) and 37 to private institutions - or companies.

Almost two decades after having implemented this diagnostic technique in Mexico there have been
Correspondence:

*Miguel Ángel Ávila-Rodríguez

E-mail: avilarod@uwalumni.com
Date of reception: 06-05-2019

Date of acceptance: 27-05-2019

DOI: 10.24875/GMM.M19000310
Gac Med Mex. 2019;155:402-410

Contents available at PubMed www.gacetamedicademexicer.com 


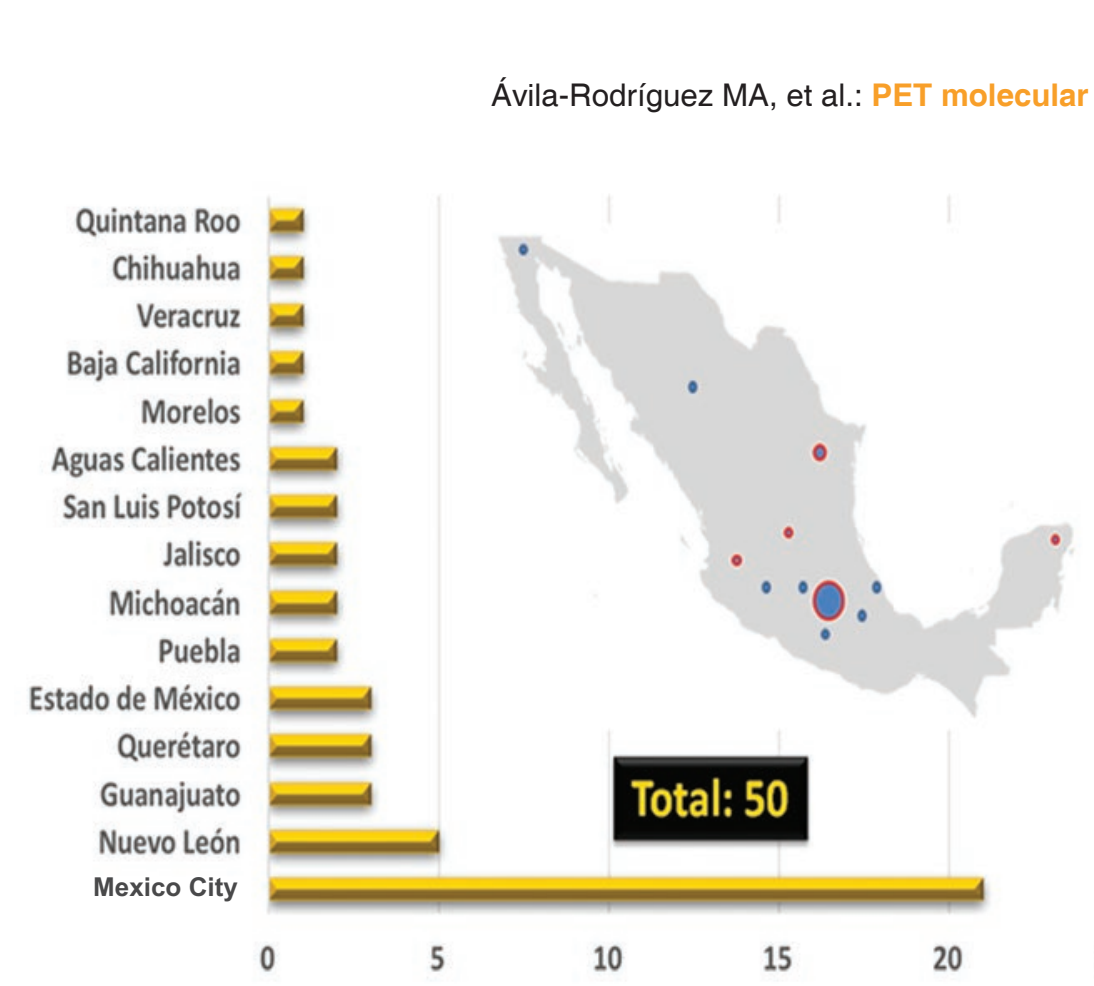

imaging in Mexio

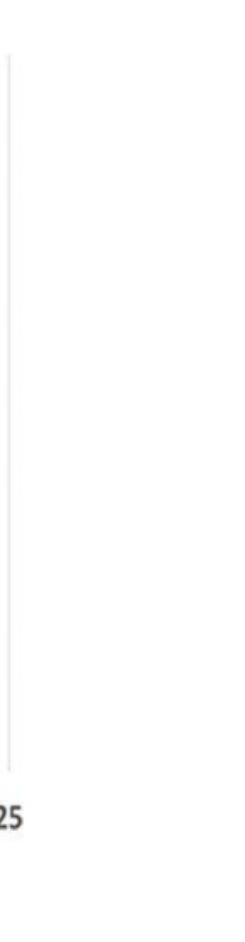

Figure 1. Distribution of PET/CT cameras in Mexico, December 2018.

Table 1. Cyclotrons in operation in Mexico, May 2019

\begin{tabular}{|c|c|c|c|}
\hline Institution/company & Sector & Brand, Energy & City \\
\hline $\begin{array}{l}\text { Faculty of Medicine, } \\
\text { UNAM }\end{array}$ & \multirow[t]{2}{*}{ Public } & $\begin{array}{l}\text { Siemens, } \\
11 \mathrm{MeV} p\end{array}$ & \multirow[t]{4}{*}{ Mexico City } \\
\hline National Cancer Institute & & IBA, $18 \mathrm{MeV} p$ & \\
\hline $\begin{array}{l}\text { Ángeles Pedregal } \\
\text { Hospital }\end{array}$ & \multirow[t]{6}{*}{ Private } & $\begin{array}{l}\text { Siemens, } 11 \\
\text { MeV p }\end{array}$ & \\
\hline $\begin{array}{l}\text { Medidores Industriales y } \\
\text { Médicos S.A. de C.V. }\end{array}$ & & GE, $16.5 \mathrm{MeV} p$ & \\
\hline OCA Hospital & & GE, 9.6 MeV p & \multirow{2}{*}{$\begin{array}{l}\text { Monterrey, } \\
\text { Nuevo León }\end{array}$} \\
\hline Doctors Hospital & & IBA, $18 \mathrm{MeV} p$ & \\
\hline Guadalajara PET & & GE, $16.5 \mathrm{MeV} p$ & $\begin{array}{l}\text { Zapopan, } \\
\text { Jalisco }\end{array}$ \\
\hline JUAMA & & $\begin{array}{l}\text { Siemens, } \\
11 \mathrm{MeV} p\end{array}$ & $\begin{array}{l}\text { León, } \\
\text { Guanajuato }\end{array}$ \\
\hline
\end{tabular}

UNAM (Universidad Nacional Autónoma de México) $=$ National Autonomous University of Mexico.

positive advances; however, its use is still highly centralized and the northern and southeastern areas of the country practically lack this technology. The World Health Organization recommends a coverage indicator of two PET/CT cameras per million population, an indicator that is fully met in developed countries. With a population of approximately 120 million, Mexico should have 240 cameras.

There are no statistics regarding the number of $\mathrm{PET} / \mathrm{CT}$ scans carried out in Mexico, although an estimate of our own indicates approximately 50 thousand every year; therefore, annually, approximately
$400 \mathrm{PET} / \mathrm{CT}$ scans per million population are carried out; considering a population of 120 million, this is a very low number in comparison with first-world cöuntries (5800 in the United States, 4400 in Japan, 1400 in Europe and 1150 in Canada). ${ }^{1}$ The cost of PEF/CT tests is high given that the technology required to perform them is expensive, although it is costliernot having it.

\section{PET molecular imaging impact}

PET molecular imaging has become an indispensable clinical tool for the best management of patients. Particularly in oncology, it has been shown to have an important impact, since it helps select the treatments with the best probabilities of success depending on the characteristics of each patient's disease, which leads to personalized or precision medicine, where the patient is treated, not the disease.

By using PET molecular imaging, it is possible to reduce direct or indirect costs associated with wröng, ineffective or unnecessary therapeutic procedures. For PET molecular imaging to be cost-effective or profitable, it should be diagnostically accurate-and effective to improve clinical management of patients, without increasing treatment cost. In a study carried out in a Spanish hospital, where 105 patients with different types of cancer were included, PE†CT studies had an influence on the clinical management of $104 / 105$ patients. $^{2}$ In half the patients (47.8 \%), the therapeutic strategy was modified and in the otherhalf 
$(51.3 \%)$ the therapeutic decision was reaffirmed. In that study, a PET/CT cost-effectiveness study was also carried out: considerable savings were recorded due to avoided therapeutic or diagnostic procedures, which were higher than the cost of the PET/CT studies that were performed. Considering all patients, the saving/cost ratio was 1.33. In prostate cancer, lung cancer and melanoma, the saving/cost ratio was 2.06 , 1.98 and 1.95 , respectively. ${ }^{2}$

Even prior to the development of PET/CT hybrid equipment, in a clinical trial carried out in 1996, where 207 patients with different types of cancer were included, the cost of the PET studies was reported to have accounted for approximately half the cost of the avoided therapeutic procedures and approximately for one quarter if the PET scan was replaced by a CT scan. ${ }^{3}$

\section{Radiopharmaceuticals}

Radiopharmaceuticals are compounds that contain radioactive atoms in their chemical structure and that owing to their pharmaceutical nature and the quantity and quality of emitted radiation are suitable for administration in human beings for diagnostic or therapeutic purposes. Radiopharmaceuticals have two main components: a molecule of biological interest that defines the metabolic route and a radioisotope that due to its radiation-emitting characteristic allows external detection. The characteristic of radiopharmaceuticals used in PET is that they are labelled with a positron emitter and that due to their short half-life are produced on demand, every day, through nuclear reactions in a cyclotron-type particle accelerator.

The success of PET molecular imaging in Mexico has walked hand in hand with nuclear pharmacy. In most commonly used radiopharmaceutical for PET scans is glucose labelled with fluor-18, commonly known as FDG, which allows glucose metabolism assessment and has very diverse applications; $90 \%$ of PET studies that are carried out in the world are formed with FDG. However, there are other radiopharmaceuticals, many of them directed to specific molecular targets, which allow evaluating physiologicaland pathophysiological processes at the molecular level, offering more specific information than that offered by FDG.

The Radiopharmacy-Cyclotron Unit of the Faculty of Medicine of the National Autonomous University of Mexico produces a wide range of radiopharmaceuticals, most of them for cancer studies. However, in recent years, the production of radiopharmaceuticals for the study of diseases related to receptor and rotransmitter dysfunction was implemented. Somè- of those used in oncology have also applications incardiology, but the most common PET study in cardiology is cardiac perfusion. In the following sections of this symposium, the applications in oncology, neurotogy and cardiology carried out in Mexico are described, as well as the specific radiopharmaceuticals used in them. 


\section{Applications in oncology}

\section{Belén Rivera-Bravo and Michel Herranz-Carnero}

The Society of Nuclear Medicine and Molecular Imaging of the United States defines molecular imaging as "the visualization, characterization and measurement of biological processes at the molecular and cellular level in humans and other living systems", ${ }^{4}$ which allows observing the intracellular metabolic pathways, receptor expression, protein synthesis, enzyme transportation, among many other processes that occur at the same time within cells and in their surroundings (environment). The ligands, molecules, proteins, antigens, receptors, etc., that intervene in these processes become molecular targets that can be labelled with positron-emitting radioisotopes and thus become radiopharmaceuticals, which allow, through PET technology, obtaining images and data to "visualize, characterize and measure" biological processes. ${ }^{4,5}$

Perhaps the most useful and best known metabolic pathway in proliferation studies is glucose metabolism (glycolysis), which in turn is the most widely used (and the first one employed) in PET. In these studies, a glucose analogue is labelled with ${ }^{18} \mathrm{Fluor}\left({ }^{18} \mathrm{~F}\right)$, thus becoming ${ }^{18} \mathrm{~F}$-fluorodeoxyglucose (FDG), a radiopharmaceutical that is highly useful in oncology, neurology and cardiology and for assessment of other pathologies, such as infectious and inflammatory processes. ${ }^{6}$ Due to its widespread use, availability and millions of performed studies, this radiopharmaceutical has become PET/CT resource par excellence.

The PET/CT equipment allows obtaining merged images of both modalities. That is, anatomical information corresponding to the CT study and functional or molecular images that result from PET. The fusion of both anatomical and functional images allows to obtain more diagnostic information and precision than it would be obtained from each study separately $(1+$ $1=3$, as its inventor, David Townsend, described in 1999). ${ }^{7}$ Therefore, PET/CT studies have become an excellent non-invasive diagnostic tool and an essential part of molecular imaging.

As for cancer, Hanahan and Weinberg ${ }^{8}$ described in 2010 the characteristic pathological processes that occur in cells and their surroundings during oncogenic transformation: sustained cell proliferation, angiogenesis, hypoxia, energy regulation alterations and inflammation, among others. These processes become potential molecular targets that can be assessed with molecular imaging, using specific radiopharmaceuticals, whereby the concept of personalized medicine, focused on and for each specific patient is increasingly getting closer. In Mexico, currently there is a wide variety of radiopharmaceuticals available for the sessment of the cancer patient (Table 2).

PET studies sensitivity and specificity depend on the pathology, i.e. the more information available on molecular characteristics of the tumor and patient clinical context, the better, and more accurately, will be the selection of the radiopharmaceutical that provide more information of the evaluated disease (Figure 2).

A breakthrough that molecular imaging has provided is "theranostics", a term that binds therapy and diagnosis in the same concept and with the same molecule. This means that the molecular targe for diagnosis is also used for treatment, i.e. the biological process is assessed with $\mathrm{PET} / \mathrm{CT}$, which allows its characterization; subsequently, the radioligand that was used for the molecular imaging study is bound to different radioactive atoms (alpha or beta emitters) and is administered to the patient for treatment. The same drug used to identify a tumor is used for treafing it. ${ }^{9}$ The above is a reality in Mexico and is carriedout in public and private institutions, where theranostics is used for neuroendocrine tumors and prostate cancer.

Another breakthrough that molecular imaging offers and that will revolutionize this field is "radiomics", a term that refers to the conversion of digital medical images into data mining to generate objective information in order to improve the process of medical decision-making..$^{10}$ The information this tool provides goes beyond that which is obtained by visual, qualitative or semi-quantitative image analysis. With no doubt, the application of mathematical algorithms to obtain objective information on images will change the way diagnostic studies are currently interpreted.

The contribution of molecular imaging to clinical practice is highly relevant: not only is information obtained through non-invasive studies on tumor $\bar{b}$ iological behavior and environment, but they also participate in the diagnosis of disease and evaluation of its extent. In the new cancer paradigm, accurate information can be provided at the molecular level to 
Table 2. Description of the radiopharmaceuticals available in Mexico for oncological use, their molecular target and main indications

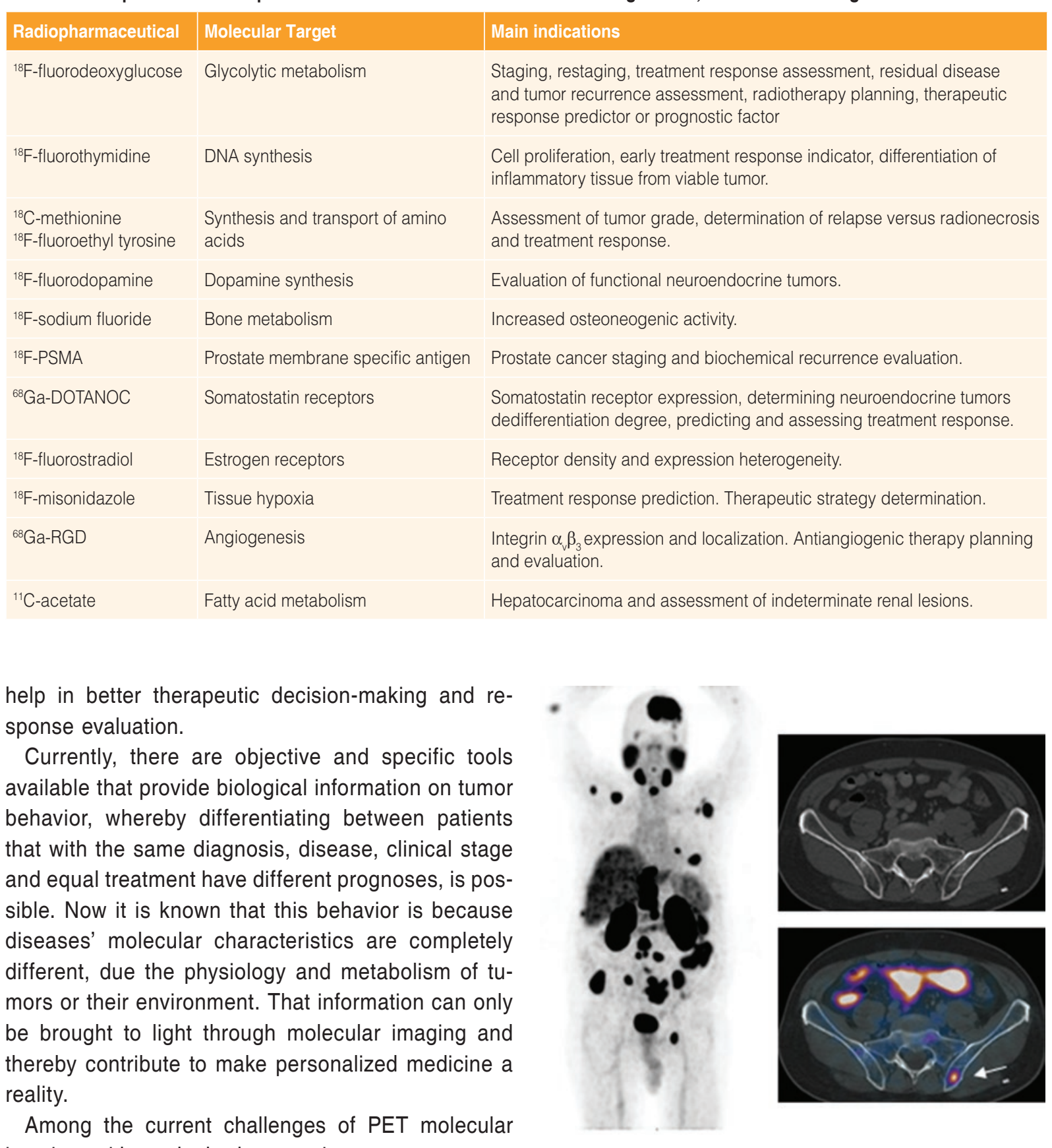
imaging, with no doubt the most important are:

- Dissemination of its usefulness and benefits in clinical decision-making.

- Accessibility to the method.

- The development of theranostics and radiomics.

These challenges and perspectives should be actively addressed in order to offer the patient the personalized medicine that is tried to be achieved.

The PET/CT Unit of the Faculty of Medicine of the National Autonomous University of Mexico has hightech and latest generation equipment, the first of its kind in Latin America. This technological improvement

Figure 2. On the left, PET scan with ${ }^{68} \mathrm{Ga}-\mathrm{PSM}$, performed for the staging of a patient with prostate cancer. In addition to radiopharmaceutical physiological biodistribution, the large extent of lymph node and bone metastatic disease is observed. On the right, computed tomography and PET/CT pelvic region axial sections of a patientwith prostate cancer referred for assessment with ${ }^{18} \mathrm{~F}$-PSMA due to biochemical recurrence. CT scan shows no detectable abnormalities while in the same of PET/CT fusion section radiopharmaceutical focal uptake is observed at the left iliac level (arrow), with no detectable anatomical changes, consistent with known primary tumor activity.

will allow to develop diagnostic studies with lower exposure of patients to radiation, with higher resolufion and better diagnostic capacity. 


\title{
Applications in neurology
}

\author{
Nora Estela Kerik-Rotenberg
}

\section{Neuro-oncology}

Primary brain tumors are a common cause of cancer with a devastating prognosis. Gliomas constitute the most common brain tumors of the central nervous system and their differentiation and histological grading are predictive of aggressiveness and prognosis. Follow-up of the tumor after surgery, chemotherapy and particularly after radiotherapy is difficult with morphological imaging modalities, since these lack the capacity to differentiate between tumor recurrence and post-radiation necrosis.

PET molecular imaging provides additional tumor metabolic (in vivo) information, both for management and for the assessment of new treatments, using energy metabolism (FDG), protein synthesis $\left({ }^{11} \mathrm{C}\right.$-methionine, ${ }^{18} \mathrm{~F}$-fluoroethyl tyrosine, ${ }^{18} \mathrm{~F}$-fluoro-Lphenylalanine) and nucleic acid ( ${ }^{18} \mathrm{~F}$-fluorothymidine), of hypoxia ( ${ }^{18} \mathrm{~F}$-misonidazole) and cell membrane component $\left({ }^{18} \mathrm{~F}\right.$-choline, ${ }^{11} \mathrm{C}$-acetate) molecular markers. ${ }^{11,12}$

Molecular imaging techniques have shown to have enormous potential for the selection candidate patients for targeted therapies as well as for treatment response assessment and, therefore, for therapeutic individualization.

\section{Dementias}

Since the 1980s, PET has been considered one of the most accurate imaging studies for Alzheimer's disease detection. In 2004, the Alzheimer's Association supported the use of FDG-PET in patients with dementia or mild to moderate cognitive impairment of at least six months' evolution.

The contribution of PET, among other things, can differentiate Alzheimer's disease from other dementias, identify groups at risk of progression, accelerate and improve the accuracy of early diagnosis and help in the development of treatments that prevent progression using $\beta$-amyloid and glucose metabolism markers.

The most commonly used radiopharmaceutical for PET is FDG. Its uptake reflects regional glucose consumption. Therefore, neuronal degeneration or dysfunction leads to the decreased glucose metabolism that occurs in different cerebral patterns. ${ }^{13}$
In Alzheimer's disease, the cerebral glucose consumption index reduction is severe, which is reflected on PET as a synaptic function and density decrease, with a sensitivity of $96 \%$ and specificity of $93 \%$. $\frac{\bar{c}}{4}$

Through PET imaging, Alzheimer's disease can be differentiated from other types of dementia, suc frontotemporal, vascular and Lewy bodies' dementia, as well as dementias associated with Huntington's and Parkinson's diseases.

\section{Movement disorders}

In recent decades, various markers have beencdeveloped for the study of patients with Parkinson's disease, in order to improve differential diagnosis with other parkinsonisms and for disease progression follow-up. Parkinson's disease is a neurodegenerative disorder characterized by progressive loss of mönoaminergic neurons, especially dopaminergic neuroons. The dopaminergic system can be studied at presynaptic and postsynaptic levels. ${ }^{14,15}$ Radioligand distrítbution normal pattern depends on normal distribution of the synaptic element to be studied.

\section{Presynaptic radioligands}

${ }^{11} \mathrm{C}$-dihydrotetrabenazine, with high affinity for monoaminergic vesicular transporter type 2, allows measuring the monoamines in synaptic vesicles (dopamine, serotonin, norepinephrine, histamine) (Fig. 3).

${ }^{18} \mathrm{~F}$-fluoro-L-phenylalanine is a dopamine precursor and levodopa analogue. In Parkinson's disease, fluorodopa uptake in the striatum, especially in the putamen, is reduced, with a correlation existing with the degree of motor alterations

\section{Postsynaptic radioligands}

${ }^{11} \mathrm{C}$-raclopride or ${ }^{18} \mathrm{~F}$-fallypride are the most commonly used compounds for the study of D2 receptors. The dopamine receptor image is characterized by $\mathrm{el}$ evated uptake in the striatum due to the high density of dopaminergic terminals in them existing.

As for Parkinsonian syndromes, they belong to a group of neurodegenerative disorders with progressive and chronic loss of neuronal tissue in the cognitive, 


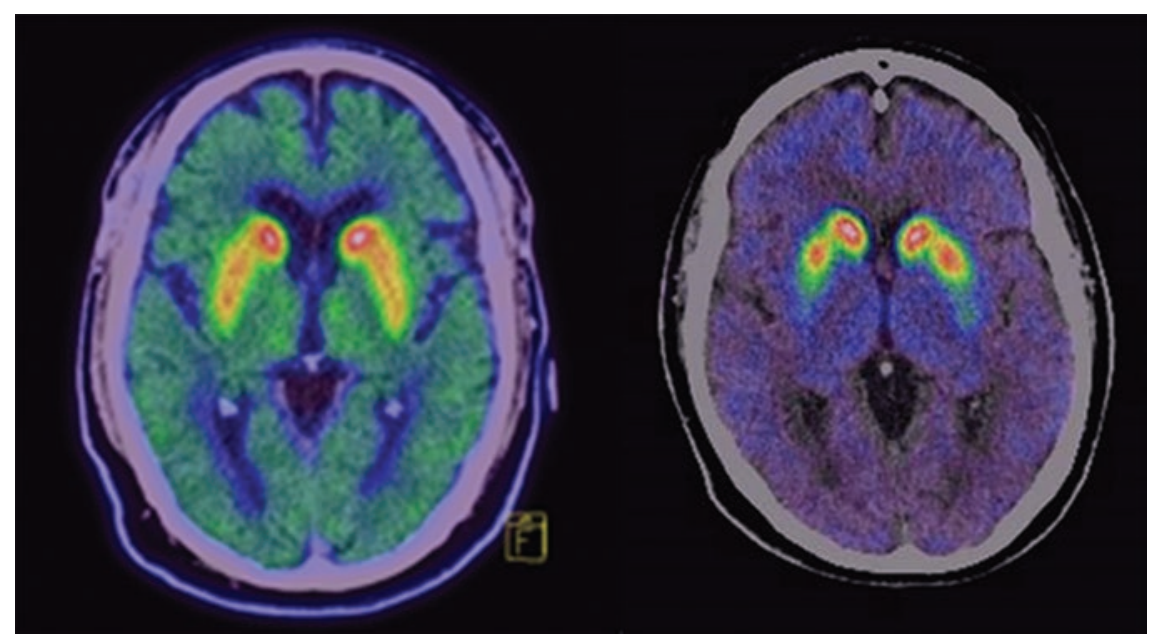

Figure 3. Image of the presynaptic dopaminergic system with ${ }^{11} \mathrm{C}$-dihydrotetrabenazine. On the left, a normal study, and on the right, severe nigrostriatal hypo-uptake, corresponding to an "Eagle wing" pattern, which is characteristic of Parkinson's disease.

motor and sensory systems. These syndromes include diseases with movement disorders, such as multiple system atrophy, corticobasal degeneration and progressive supranuclear palsy, Huntington's disease, amyotrophic lateral sclerosis and prion disease, such as Creutzfeldt-Jakob disease. These diseases can be identified with multiple degrees of cortical and nigrostriatal system involvement. PET molecular imaging allows to further approach to a more accurate differential diagnosis to in vivo assess the mechanisms responsible for the neurodegenerative processes.

\section{Epilepsy}

In a significant proportion of patients with epilepsy, $30 \%$ of complex partial seizures are treatment-refractory despite therapeutic efforts. The selection of patients with no response to medical treatment and candidates for surgery essentially requires a correct pre-surgical localization of the epileptogenic zone and the prediction of the possible sequels of the intervention. Currently, PET-FDG is used for metabolic localization of the epileptogenic zone prior to surgery, with a sensitivity of 80 to $90 \%$ for temporal lobe epilepsy, ${ }^{16}$ and 45 to $92 \%$ for extra-temporal epilepsy. ${ }^{17}$ The purpose of the assessment is to determine if there is evidence of a single epileptic focus, determine- its dissemination pathways and its relationship with possible structural injury.

\section{Neurology}

One of current PET/CT applications is encephaitis differential diagnosis. ${ }^{18}$ Autoimmune encephalitides are a new category of central nervous system inflammatory diseases mediated against neurotransmitter or neuronal surface protein antibodies. Clinical syndromes are complex and are associated with manifestations that vary depending on the type of associated antibody. Autoimmune response can be initiated by a tumor or viral infection, but in many cases this is not known. The use of PET-FDG has been of the utmost importance for differential diagnosis, follow-up, treatment assessment and patient prognosis. It also provides information at the metabolic biochemical-molecular level in vivo, and thus it is an excellent tool to assess brain metabolism and rule out possible sites of malignancy since early stages. 


\section{Applications in cardiology}

\section{Enrique Vallejo and Christian Buelna-Cano}

PET evaluates and quantifies with certainty myocardial viability, myocardial perfusion, coronary flow reserve (CFR), inflammatory and Infectious processes and tissue damage..$^{19,20}$

\section{Assessment of myocardial viability}

Assessment of myocardial viability is indicated in patients with myocardial infarction and systolic dysfunction (left ventricular ejection fraction $[\mathrm{LVEF}]<0.35$ ). The concept of myocardial viability was created to describe cells with metabolic activity and without contractile function after infarction. ${ }^{21}$ PET diagnostic imaging in myocardial viability is the discordance between perfusion and metabolism, i.e., myocardial perfusion defects but FDG uptake thanks to cell metabolism. The study of myocardial viability with PET in patients with LVEF $<0.35$ differentiates ventricular segments with contractile reserve ( $85 \%$ positive predictive value) from the segments without contractile reserve (negative predictive value of $92 \%$ ) after of coronary artery bypass grafting (CABG). The percentage of myocardial viability necessary to infer survival improvement with $C A B G$ is $7 \%{ }^{22,23}$

\section{Myocardial perfusion assessment}

PET offers advantages in comparison with single photon-emission computed tomography for the assessment of myocardial perfusion, since it quantifies global myocardial flow and regional flow. Based on these quantitative parameters, CFR, which is defined as the difference between maximum myocardial flow under stress and myocardial flow at rest, can be calculated. ${ }^{24}$ With these parameters, PET identifies patients with CFR-limiting atheromatous plaque or microvascular disease. CFR quantification is accurate and has a high prognostic value in patients with suspected coronary artery disease..$^{25}$ Coronary flow normal values calculated with ${ }^{13} \mathrm{~N}$-ammonia are, at rest, $0.71 \mathrm{~mL} /$ minute $/ \mathrm{g}$, and under stress, $2.58 \mathrm{~mL} /$ minute $/ \mathrm{g}$. CFR normal value is 3.54. A CFR $>2$ has a high negative predictive value to rule out high-risk coronary artery disease, even in patients with trivascular disease. A global CFR $<1.5$ is associated with increased mortality from cardiovascular causes. ${ }^{26}$ In patients with diabetes mellitus without obstructive coronary artery disease, but with abnormal CFR, PET identifies a group of patients with high cardiovascular risk, equivalent to that of patients with obstructive coronary artery disease. ${ }^{27}$

\section{Inflammation assessment}

Cardiac PET assesses atherosclerosis as an immune-inflammatory phenomenon. The atherosclerosis process is a result of inflammation; it starts. With monocyte activation and differentiation into macrophages in the vascular sub-endothelium, and which in turn become foam cells. These cells form part of the atherosclerotic plaque, composed of a lipid nucteus that in a complex inflammatory response give rise to microcalcifications. PET radiotracers focus. the components of atherosclerosis: inflammatory cells, lipids and fatty acids, in addition to angiogenesis, proteases, thrombosis, apoptosis tand microcalcifications. ${ }^{28}$

Imaging with ${ }^{18} \mathrm{FDG}$ and ${ }^{18} \mathrm{~F}$-sodium fluoride altows identifying atheromatous plaques and characterizing high-risk vulnerable plaques. ${ }^{18} \mathrm{~F}-\mathrm{FDG}$ uptake reflects inflammation and ${ }^{18} \mathrm{~F}$ - sodium fluoride uptake is rêtated to microcalcification. ${ }^{29}$

\section{Infection assessment}

${ }^{18} \mathrm{~F}-\mathrm{FDG}$ PET is useful in the diagnosis and follow-up of infective endocarditis, intracardiac device infection, ventricular assistance device infection and vascular graft infection. The most common application is in patients with endocarditis. This technique chas improved diagnostic sensitivity in combination with the Duke criteria, with a sensitivity of $95 \%$, specificity of $90 \%$, positive predictive value of $91 \%$ and negative predictive value of $95 \%$ being reached. When ${ }^{18}$ F-FDG PET is added to echocardiographic findings, the ditagnostic value is significantly increased (96 versus $65 \%$ ), favoring early intervention and avoiding serious complications such as perivalvular abscesses fand atrioventricular block. ${ }^{30} \mathrm{~A}$ quantitative measurement of ${ }^{18}$ F-FDG standard uptake value $>2$ has $100 \%$ šensitivity and $92 \%$ specificity to identify prosthetic valtye endocarditis. ${ }^{31}$ 
Intracardiac device-associated infections cause high morbidity and mortality. ${ }^{18} \mathrm{~F}-\mathrm{FDG}$ PET is indicated when the diagnosis has not been able be confirmed with echocardiography; it has sensitivity and specificity of 96 and $97 \%$, respectively. ${ }^{30}$

\section{Tissue damage assessment}

Bioprosthetic valve degeneration pathophysiology is currently a subject of research. Valvular tissue calcification is an initial component in this process and can be identified before clinical manifestations of valvular dysfunction appear. Cardiac PET with ${ }^{18}$ F-fluoride identifies valve microcalcifications, supporting the hypothesis that with PET it is possible to detect valve degeneration at subclinical stages; therefore, it is considered that, in the future, it will be a useful tool in the search for new treatments to stop the valve degenerative process. ${ }^{32}$

\section{References}

1. Azaiez F, Cantone MC. Radioisotope production. En: Azaiez F, Bracco A Dobes J, Jokinen A, Körner GE, Maj A, et al., editores. Nuclear physics for medicine, Francia: European Science Foundation/Nuclear Physics European Collaboration; 2013.

2. Alemany N, Pérez-De Olaguer J, Bertomeu M, Trampal B. Clinical impact and cost-effectiveness of PET-CT in the management of oncologic patients. España: European Society of Radiology; 2013.

3. Valk PE, Pounds TR, Tesar RD, Hopkins DM, Haseman MK. Cost effectiveness of PET imaging in clinical oncology. Nucl Med Biol. 1996;23:737-743

4. Delbeke D, Royal HD, Frey KA, Graham MM, Segall GM. SNMI/ABNM joint position statement on optimizing training in nuclear medicine in the era of hybrid imaging. J Nucl Med. 2012;53:1490-1494.

5. Wester HJ. Nuclear imaging probes: from bench to bedside. Clin Can Res. 2007:13:43-48.

6. Boellaard R, Delgado-Bolton R, Oyen WJG, Giammarile F, Tastch K, Eschner W, et al. FDG PET/CT: EANM procedure guidelines for tumour imaging: versión 2.0. Eur J Nucl Med Mol Imaging. 2015;42:328-354.

7. Townsend DW. Positron emission tomography/computed tomography. Semin Nucl Med. 2008;38:152-166.

8. Hanahan D, Winberg RA. Hallmarks in cancer: the next generation. Cell. 2011;144:646-674.

9. Yordanova A, Eppard E, Kürpig S, et al. Theranostics in nuclear medicine practice. Onco Targets Ther. 2017;10:4821-4828.

10. Gillies RJ, Kinahan PE, Hricak H. Radiomics: imaging are more than pictures, they are data. Radiology. 2016:278:563-577.
11. Herholz K. Brain tumors: an update on clinical PET research in gliomas. Semin Nucl Med. 2017;47:5-17.

12. Yamamoto $Y$, Nishiyama $Y$, Kimura N, Kameyama R, Kawai N, Hatakeyama $\mathrm{T}$, et al. $11 \mathrm{C}$-acetate $\mathrm{PET}$ in the evaluation of brain glioma:comparison with $11 \mathrm{C}$ methionine and $18 \mathrm{~F}$ FDG PET. Mol Imaging $P$ Bol 2008;10:281-287.

13. Silverman D, editor. PET in the evaluation of Alzheimer's disease- and related disorders. EE. UU.: Springer; 2009.

14. Berti V, Pupi A, Mosconi L. PET/CT in diagnosis of movement disorders. Ann N Y Acad Sci. 2011;1228:93-108.

15. Juri C, Wanner V. Neuroimágenes en enfermedad de Parkinson: Yol de la resonancia magnética, el SPECT y el PET. Rev Med Clin Coṇdes. 2016;27:380-391.

16. Cendes F, Theodore WH, Brinkmann BH, Sulc V, Cascino GD. Neuroimaging of epilepsy. Handb Clin Neurol. 2016;136:985-1014.

17. Kumar A, Chugani $H$. The role of radionuclide imaging in epilepsy, part 2: epilepsy syndromes. J Nucl Med. 2013:54:1924-1930.

18. Morbelli S, Arbizu J, Booij J, Chen MK, Chetelat G, Cross DJ, et al. The need of standarization and of large clinical studies in an emerging-indication of $\left.{ }^{18} \mathrm{~F}\right]-\mathrm{FDG}$ PET: the autoinmune encephalitis. Eur J Nuet-Med Mol Imaging. 2017;44:353-357.

19. Vallejo E. El futuro del PET en cardiología. Arch Cardiol Mex. 2002:72:220-225.

20. Bateman T, Dilsizian V, Beanlands R, DePuey G, Heller G, Wolinsky D. American society of nuclear cardiology and society of nuclear medicine and molecular imaging joint position statement on the clinical indications for myocardial perfusion PET. J Nucl Med. 2016;57:1654-1656.

21. Anevekar N, Chareonthaitawee P, Narula J, Gersh B. Revascularization in patients with severe left ventricular dysfunction. J Am Coll Cardiol. 2016;67:2874-2887.

22. Loffler AI, Kramer CM. Myocardial viability testing to guide coronary revascularization. Intervent Cardiol Clin. 2018:7:355-365.

23. Allman K. Noninvasive assessment myocardial viability: current status and future directions. J Nucl Cardiol. 2013;20:618-637.

24. Pelletier-Galarneau M, Martineau P, El-Fakhri G. Quantification of PET myocardial blood flow. Curr Cardiol Rep. 2019;21:11.

25. Dilsizian V, Chandrashekhar Y, Narula J. Quantitative PET myocardial blood flow. JACC: Cardiovascular Imaging. 2017;10:609-610.

26. Murthy V, Bateman T, Beanlands R, Berman D, Borges S, Chareonthaitawee $\mathrm{P}$, et al. Clinical quantification of myocardial blood flow using PET: Joint position paper of the SNMMI cardiovascular council and the ASNC. J Nucl Med. 2018;59:273-293.

27. Murthy V, Naya M, Foster C, Gaber M, Hainer J, Klein J, et al. Asšociation between coronary vascular dysfunction and cardiac mortality in patients with and without diabetes mellitus. Circulation. 2012:126: 1858-1868.

28. Flemming PF, Moghbel MC, Gerke O, Alavi A. Evolving role of PEET in detecting and characterizing atherosclerosis. PET Clin. 2019;14:19\%-209.

29. Moghbel M, Al-Zaghal A, Werner T, Mihail C, Flemming P, Alavi AD The role of PET in evaluating atherosclerosis: a critical review. SeminNucl Med. 2018;48:488-497.

30. Millar BC, De Camargo RA, Alavi A, Moore JE. PET/computed tomography evaluation of infection of the heart. PET Clin. 2019;14:251-269.

31. Swart LE, Gomes A, Scholtens A, Sinha B, Tanis W, Lam M, et al. Improving the diagnostic performance of $18 \mathrm{~F}$-Fluorodeoxyglucose positron emission tomography in prosthetic heart valve endocarditis. Circulation. 2018:138:1412-1427.

32. Cartlidge TRG, Doris M, Sellers S, Pawade T, White A, Pessotto R, cet al. Detection and prediction of bioprosthetic aortic valve degeneration $7 \mathrm{Am}$ Coll Cardiol. 2019;73:1107-1119. 